\title{
Effect of tempering after cryogenic treatment of tungsten carbide-cobalt bounded inserts
}

\author{
NIRMAL S KALSI*, RAKESH SEHGAL ${ }^{\dagger}$ and VISHAL S SHARMA ${ }^{\#}$ \\ Department of Mechanical Engineering, Beant College of Engineering \& Technology, Gurdaspur 143 521, India \\ $\dagger$ Department of Mechanical Engineering, National Institute of Technology, Hamirpur 173 742, India \\ \# Department of Industrial and Production Engineering, National Institute of Technology, Jalandhar 144 001, India
}

MS received 10 March 2012; revised 24 September 2012

\begin{abstract}
Cryogenic treatment is a recent advancement in the field of machining to improve the properties of cutting tool materials. Tungsten carbide is the most commonly used cutting tool material in the industry and the technique can also be extended to it. Although the importance of tempering after cryogenic treatment has been discussed by many researchers, very little information is available in published literature about the effect of multi-tempering after cryogenic treatment. In this study, an attempt has been made to understand effect of the number of posttempering cycles during cryogenic treatment on tungsten carbide-cobalt inserts. Metallurgical investigations have been performed to observe the effect of such post-tempering on the inserts by analysing microhardness and microstructural changes. The crystal structure and morphology were characterized by scanning electron microscopy, energy dispersive X-ray spectroscopy and X-ray diffraction analysis. Metallurgical investigations revealed a significant improvement in tungsten carbide inserts having three tempering cycles, after cryogenic treatment, with marginal differences for two cycles of tempered inserts, established by the study of wear behaviour in turning.
\end{abstract}

Keywords. Cryogenic treatment; tungsten carbide-cobalt; SEM; XRD; microhardness.

\section{Introduction}

Tungsten carbide tools can machine metals at speeds that cause the cutting edge to become red hot, without losing its hardness or sharpness. It exhibits about 2-3 times the productivity and 10 times the life of high-speed steel tools on machining non-ferrous materials (Krar et al 2008). Tungsten carbide (WC) belongs to a class of wear-resistant refractory material (cemented carbides), and can have a metal binder such as $\mathrm{Co}, \mathrm{Fe}$ and $\mathrm{Ni}$. The properties of these materials are addressed by their phases, namely the hard and brittle carbides, and the softer, more ductile binders. Cobalt is next to iron in the periodic table as part of VIII B group, has the same valences as iron and forms similar phases in crystalline structures (Stewart 2004). Although other metal carbides, such as $\mathrm{TiC}, \mathrm{NbC}, \mathrm{TaC}$, etc. have also been used in cutting tools, around $95 \%$ of all cemented carbide cutting tools are tungsten carbides based (Sarin 1981). Life of a cutting tool plays an important role for improving productivity, and consequently is a major economic factor.

Over the past century, many manufacturing methods have been attempted to improve mechanical performance of cemented carbides. Recently, cryogenic treatment (CT) has been reported improving the properties of the materials. It is the process of cooling a substance to a temperature, generally around $196^{\circ} \mathrm{C}$, in order to improve its service life.

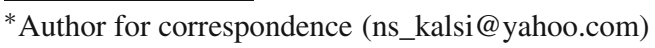

Many researchers have reported the mechanisms responsible for the improvement in properties of steels (Choi et al 2003; Bensely et al 2005; Cajner et al 2009; Podgornik et al 2009). However, scientific research describing the effect of CT on metallurgical and mechanical properties of WC-Co material has been rare, and only a few academic papers have been published (Lavergne et al 2002; Gill et al 2010, 2012; Kalsi et al 2010). It was observed that deep CT introduced some physical changes that could be due to cobalt densification. Tungsten being the harder and more stable phase, the changes were expected in cobalt binder only (Steward 2008). Similar results were reported by Thakur et al (2008). In their SEM analysis of tungsten carbidecobalt micrographs, they concluded that the cobalt densification which occurred held the carbide particles more firmly resulting in increased wear-resistance in the inserts. Gisip et al (2009) also confirmed the same and concluded that cobalt binder was retained better and exhibited a minimum high-temperature oxidation or corrosion deterioration. Similarly, Vadivel and Rudramoorthy (2009) concluded the same basics. Bryson (1999) attributed the wear-resistance, and hence the increase in tool life, of carbide tools to the improvement in the holding strength of the cobalt binder after CT. Stewart (2004) in his study concluded that cryo-processing has an effect upon the cobalt binder by changing the phase or crystal structure so that more cobalt binders were retained during cutting. Gallagher et al (2005) also showed similar results. 
Seah et al (2003) attributed increase in wear-resistance of tungsten carbide after CT to an increase in the number of $\eta$-phase particles which are harder in nature, a theory which is supported by SEM micrographs. Increase in population of $\eta$-phase carbides was also confirmed by Thakur et al (2008). They also confirmed a slight increase in the micro-hardness in tungsten carbide tools due to $\mathrm{CT}$, which was due to formation of additional complex carbides such as $\mathrm{Co}_{6} \mathrm{~W}_{6} \mathrm{C}$ or $\mathrm{Co}_{3} \mathrm{~W}_{3} \mathrm{C}$. Gill et al (2012) in their study reported an increase of $4.75 \%$ in the hardness after shallow CT and mentioned that there was no further increase due to deep CT. Improved wearresistance of the WC-Co inserts was reported by Vadivel and Rudramoorthy (2009) after CT, which enhanced the hardness in the tools. Reddy et al (2007) in their study on carbide turning inserts, subjected to normal and deep cryogenic processing, noted better service life compared to untreated inserts in terms of flank wear. In their other studies (Reddy et al 2008, 2009) on P-30 tungsten carbide inserts while machining $\mathrm{C} 45$ steel, they also observed improvement in flank wear of $21.2 \%$ and tool life of $11.1 \%$ after CT. Due to this, the main cutting forces during machining were reduced compared to untreated inserts. Yong et al (2006, 2007) in their two independent studies illustrated that the CT of WC-Co improved the life of cutting tool in terms of flank wear of milling and turning operations. They concluded that tools under mild cutting conditions stand to gain maximum from CT. However, heavy-duty long cutting operations will not benefit from it due to high heat involvement. Gill et al (2008) in their study reported that cryogenically treated tungsten carbide inserts which were subjected to two tempering cycles, performed better compared to untreated inserts. Kalsi et al (2012) in their study, followed variable number of post-tempering cycles during the cryogenic treatment of tungsten carbide inserts. The highest reduction found in tool flank wear was $26 \%$ and power consumption was around $20 \%$ with better surface finish of the workpieces, by using triple tempered cryogenically treated inserts.

The literature review reveals the contribution of CT in improving the properties of tungsten carbides, but the work does not adequately clarify the choice of the number of post-tempering cycles during CT. However, the importance of tempering was well established (Yang et al 2006; Kalsi et al 2010, 2012; Bal 2012). Keeping in view the need of standardizing the cycle for its maximum utilization, the current study therefore was conducted by considering multitempering after CT on WC-Co inserts. The analysis was carried out to understand the metallurgical changes responsible for improving the properties of the inserts, further followed by wear analysis in turning.

\section{Experimental}

In this study, Kennametal tungsten carbide-cobalt alloy ISO CCMT09T304LF (W: $82.59 \%$, C: $6 \cdot 01 \%$, Co: $11.40 \%$ ) cutting tool inserts were selected. The standard microprocessor based cryogenic processor (model no. CP 220 LH by
Primero EnServe Pvt. Limited, Chennai, India) was used in this study with operating range of $-30{ }^{\circ} \mathrm{C}$ to $-196{ }^{\circ} \mathrm{C}$ and cooling/heating rate to $1^{\circ} \mathrm{C}$. Four lots of commercially available inserts were frozen to $-196{ }^{\circ} \mathrm{C}$ from the room temperature, reducing the temperature gradually at the rate of $1{ }^{\circ} \mathrm{C} / \mathrm{min}$. The samples were soaked for $24 \mathrm{~h}$ and brought back to the normal temperature gradually at the same rate of $1{ }^{\circ} \mathrm{C} / \mathrm{min}$. Continuing the same rate of change of temperature, the inserts were tempered at $+200{ }^{\circ} \mathrm{C}$, following the cycle as shown in figure 1 , and the first lot of samples was removed for analysis (CT1). The remaining lots were tempered for the second (CT2), third (CT3) and fourth (CT4) tempering cycles and removed for analysis. In this study, the inserts were treated under dry conditions in a sealed chamber, where direct contact of the inserts with liquid nitrogen was avoided to eliminate the risk of thermal shock/crack. Also, in order to avoid the risk of thermal shock/crack due to sudden cooling and heating, the inserts were exposed to these temperatures at a very slow cooling and heating rate. A completely computer-controlled process was applied to minimize any chance of error.

The metallographic microstructure was determined according to ASTM B390-92 (2000). Micrographs were taken at $3000 \times$ magnification after etching with Murakami's solution, using a JSM-6610LV Scanning Electron Microscope of JEOL USA. The chemical compositions of untreated and all cryogenically treated inserts were examined using energy dispersive X-ray spectroscopy (EDS) technique. Micro-hardness testing was carried out using a DHV 1000 micro-hardness tester with a Vicker's indenter under a load of $9.807 \mathrm{~N}$, and a dwell time of $15 \mathrm{~s}$. An average value of five data points on each sample was taken to reduce the chances of error. X-ray diffraction (XRD) was used to examine the crystal structure of the inserts to identify any phase change that took place after the treatments. X'Pert Pro MPD diffractometer by PANalytical, Netherlands using $\mathrm{CuK} \alpha$ radiation, was used to investigate the various phases in crystalline structure. The examination was first based upon HighScore Plus 3.0e software and then integrated computer based automated search/match was carried out using International Centre for Diffraction Data (ICDD) database to identify the existing peaks/compounds in the material.

Wear rates of the tungsten carbide cutting tool inserts were evaluated in turning AISI 1040 steel workpieces. After the workpieces (60 $\mathrm{mm}$ diameter) were cut off in required length of $400 \mathrm{~mm}$, they were hardened at HRC 40 and then tempered at $200{ }^{\circ} \mathrm{C}$ to remove residual stresses and to obtain a homogeneous structure. Cutting tests were performed on the workpieces, where the hardness was within the limits of $\pm 5 \%$ and an average value of principal flank wear of inserts after each cutting operation was recorded. Fresh cutting edges were used in each cutting condition, and four cutting runs were performed to obtain an average of maximum flank wear. Since the width of flank wear was not regular along the cutting edge, the principal flank wear was evaluated by the method in accordance to ISO 3685 (1993). The maximum flank wear was measured by using a metallurgical 


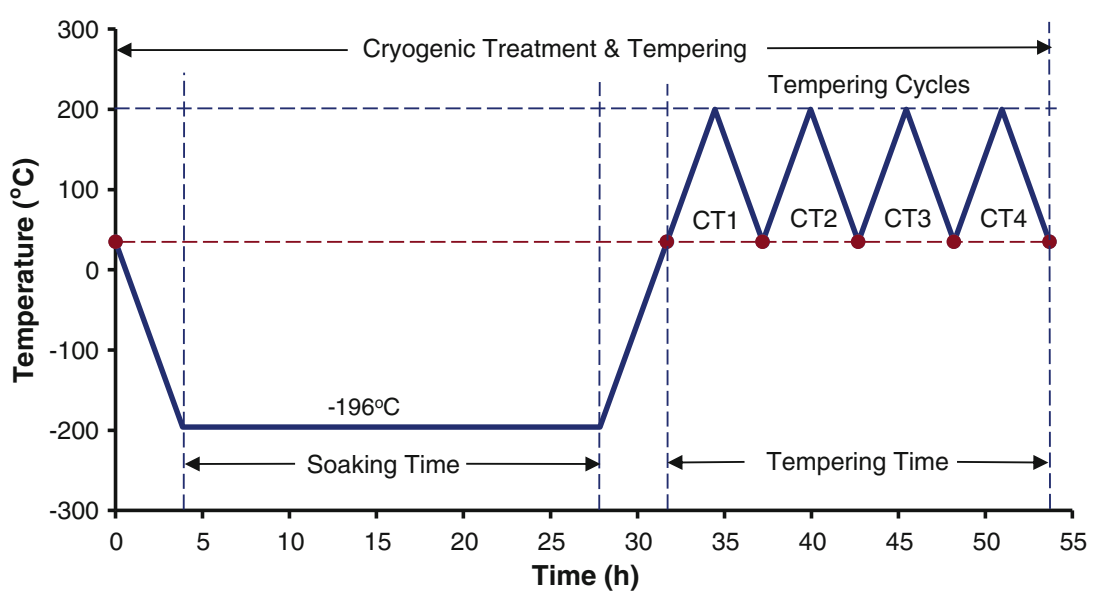

Figure 1. Detailed cryogenic treatment cycle.

microscope (Yocon, Japan) on each insert. Since life of a cutting tool is most influenced by cutting speed, followed by feed rate and depth of cut (Oberg et al 2004; Richetti et al 2004), here cutting speed $(42.2,87.18$ and $124.17 \mathrm{~m} / \mathrm{min})$ and feed rate $(0.04,0.057$ and $0.08 \mathrm{~mm} / \mathrm{rev})$ were considered based upon preliminary turning tests, and the depth of cut was kept constant at $0.75 \mathrm{~mm}$.

\section{Results and discussions}

\subsection{Metallography analysis of microstructure}

Figure 2 shows the microstructure of untreated and post multi-tempering cryogenically treated inserts. The following phases are present in the metallographic microstructure as per ASTM B657-92 (2000) standard: the first phase comprising gray uneven angular shapes represents tungsten carbide grains ( $\alpha$-phase); the second phase consisting of white vein like regions signifies cobalt binder ( $\beta$-phase); and the third phase comprising multiple carbide tungsten with at least one metal binder, known as $\eta$-phase, appears as dark-gray specks. The $\gamma$-phase, which comprises carbides of a cubic lattice (e.g. $\mathrm{TiC}, \mathrm{TaC}, \mathrm{NbC}$, etc.) was insignificant because the selected grade contains tungsten carbide and cobalt, and did not contain any other element/carbide as per EDS/XRD analysis. Unevenly distributed and coarse structures were observed for untreated WC-Co (figure 2a) compared to all treated inserts. The volume fraction of $\alpha$-phase was higher in the WC-Co inserts and was present in the form of clusters of particles spread throughout entire bulk of the material compared to treated inserts. This tungsten carbide phase was stable and stoichiometric, with no significant difference in grain size after various treatments, figure 2(b)-(e). Cobalt binder ( $\beta$-phase) was shrunk and shaped like a dense microstructure after the treatments (CT1, CT2 and CT3), and formed a continuous network around WC. However, the CT4 treated inserts (figure 2e) showed some physical changes, which indicate a reduced effect of CT after applying more post-tempering cycles during the CT. Cobalt was scattered, and the surface was uneven compared to the other treated inserts. The presence of $\eta$-phase carbides cannot be neglected in untreated WC-Co. However, it is obvious from figure 2(a) that untreated WC-Co contained few and little dispersed $\eta$-phase carbides. Holding samples at a low temperature for a long time during CT resulted in precipitation of carbide particles in a fine and more uniform distribution after the tempering, figure 2(b)-(e), which is further analysed in XRD study. The inserts treated at CT1, CT2 and CT3 were observed having a fine and compact microstructure of the most suitable form, and did not show any noticeable surface morphology change. However, the microstructure reverted to the starting state with more than three tempering cycles after the cryogenic treatment (figure 2e).

It is known that strong metallic bonds exist between cobalt atoms ( $\beta$-phase) and the carbon atoms of the hard phase ( $\alpha$-phase). Large grains of cobalt binder are often found in the structure of WC-Co as in figure 2(a), which weaken the strength in the material. It is well-known that the grain size of the cobalt can reach up to $1 \mathrm{~mm}$, so that one single cobalt grain builds the matrix for many micron-size $\alpha$-phase grains. An important parameter for the mechanical properties is therefore the mean free path of the binder, which is the average distance between two cobalt/carbide particles. It is evident from figure 2(b)-(e) that the WC particles ( $\alpha$-phase) came closer to each other and made the structure compact compared to untreated inserts. This was due to shrinkage and densification of the cobalt binder ( $\beta$-phase) after the treatments, as also indicated by earlier studies (Stewart 2004; Thakur et al 2008; Gisip et al 2009; Vadivel and Rudramoorthy 2009). The contraction of $\beta$-phase after the treatment brought the carbide particles closer to reduce the free path, to improve the properties of the WC-Co. Tungsten being the hard and stable phase, physical change was expected to be in the cobalt binder ( $\beta$-phase) only. Contraction of the cobalt in WC-Co after the treatment also confirmed from EDS results (table 1), which indicate the gain in $\mathrm{C}$ and Co contents, and corresponding decrease of $\mathrm{W}$, 


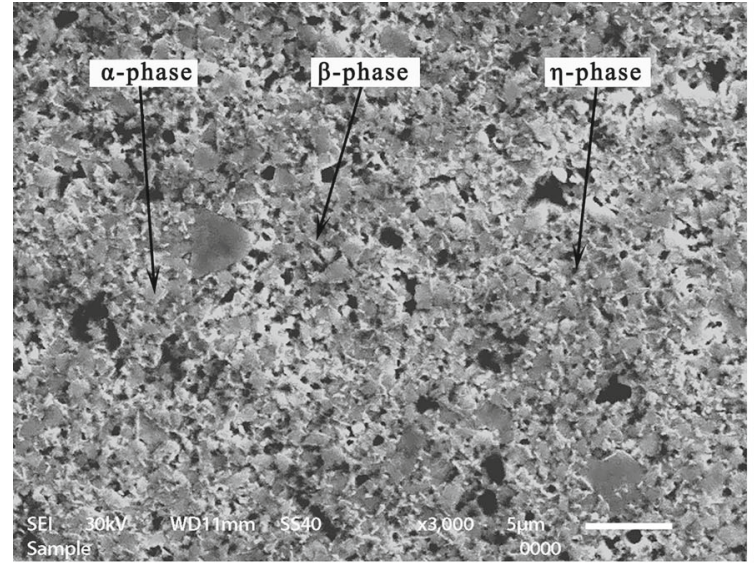

(a)

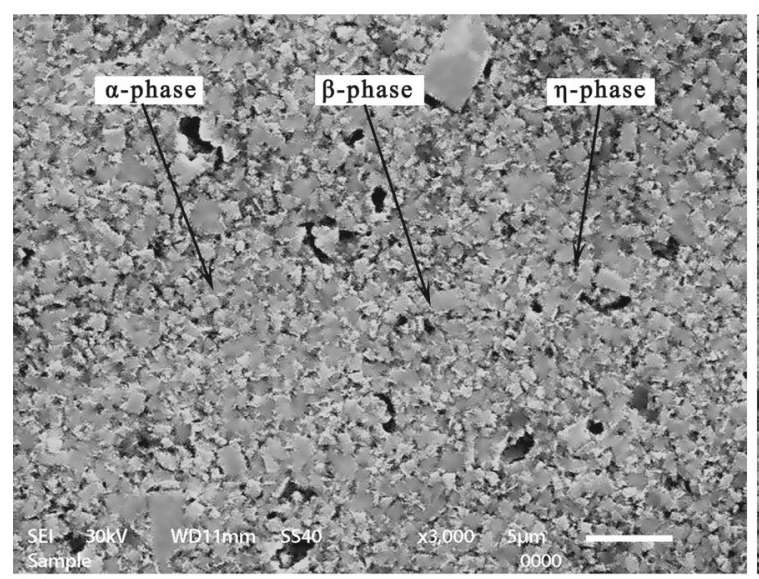

(c)

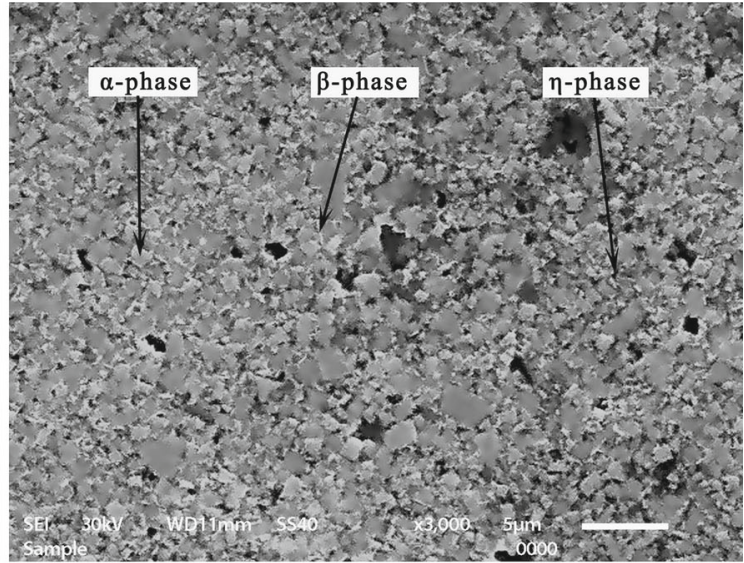

(b)

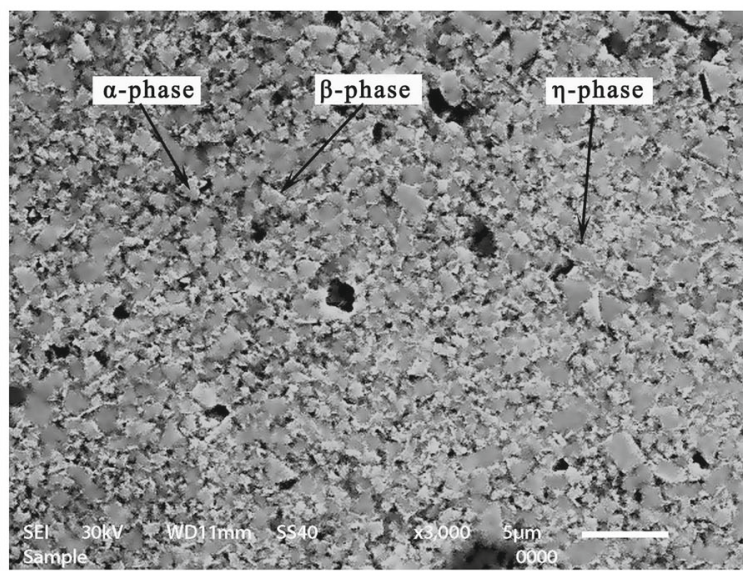

(d)

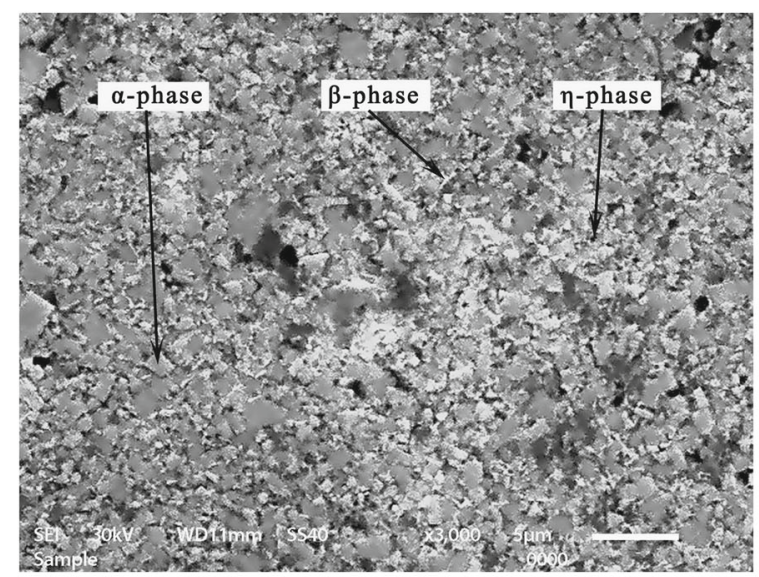

(e)

Figure 2. SEM image in secondary mode: (a) un-treated, (b) CT1 treated, (c) CT2 treated, (d) CT3 treated and (e) CT4 treated.

Table 1. EDS analysis of the inserts.

\begin{tabular}{|c|c|c|c|c|c|c|}
\hline \multirow[b]{2}{*}{ Serial no. } & \multirow[b]{2}{*}{ Element } & \multicolumn{5}{|c|}{ Average atomic percentage } \\
\hline & & Untreated & CT1 & CT2 & CT3 & $\overline{\mathrm{CT} 4}$ \\
\hline 1. & $\mathrm{C}$ & $44 \cdot 8$ & $52 \cdot 8$ & $50 \cdot 3$ & $49 \cdot 7$ & $47 \cdot 5$ \\
\hline 2. & $\mathrm{Co}$ & $14 \cdot 8$ & $16 \cdot 2$ & $16 \cdot 1$ & $15 \cdot 7$ & $15 \cdot 1$ \\
\hline 3. & W & $40 \cdot 4$ & $31 \cdot 1$ & $33 \cdot 6$ & $34 \cdot 6$ & $37 \cdot 4$ \\
\hline
\end{tabular}


when examined following the area mapping during the analysis. The gain in percentage was maximum in case of CT1 treated inserts. Further increase in the number of tempering cycles after cryogenic treatment must have exposed little expansion of the material, which tried to revert the status and the atomic percentage of the elements was also reduced (table 1). The $\beta$-phase crystal is hexagonal at room temperature and undergoes a first-order phase transition from close packed hexagonal to face centered cubic, at $417{ }^{\circ} \mathrm{C}$ during its manufacturing (Buss 2004). It is possible that this face centered cubic crystal structure does not get transferred to its original hexagonal form due to the internal stresses in WC-Co, while coming back to the room temperature. After bringing WC-Co to its lowest energy level during cryogenic treatment, tempering might have relieved the stresses and helped the $\beta$-phase crystals to be rearranged in relatively stable and closed packed hexagonal structure, thereby helping $\alpha$-phase crystals to be aligned in a suitable stress-free crystallographic form (figure $2 \mathrm{~b}-\mathrm{d}$ ). So, a continuous and homogeneous structure throughout the sample was observed in case of CT1, CT2 and CT3 treated inserts compared to untreated inserts. It is believed that fine microstructure has also formed stronger metallic bonds between the cobalt and tungsten, after the cryogenic treatment that created a resilient adhesion of the two phases. This gave additional strength to the WC/Co interface to make the WC-Co material better wear-resistant. Depleting effect after CT4 treatment revealed that more tempering cycles after the cryogenic treatment produced disruptions in the cobalt binder and hence coarsening of the grain size, due to which the material deteriorated.

\subsection{Energy dispersive X-ray spectroscopy analysis (EDS)}

Table 1 shows the percentage variation in different phase elements for the untreated and all treated inserts. There was an increase in $\mathrm{C}$ and Co content, and corresponding decrease of W content after CT1 treatment of the inserts compared to untreated inserts. However, subsequently there was a marginal decrease in $\mathrm{C}$ and Co content, and corresponding increases of $\mathrm{W}$ content were observed with increasing numbers of tempering cycles after the cryogenic treatment. Although the values of $\mathrm{C}$ and Co content decreased gradually with more tempering cycles after the cryogenic treatment, these were higher (C: $47.5 \%$ and Co: $15.1 \%$ ) for CT4 treated inserts compared to the untreated inserts (C: $44.8 \%$ and Co: $14.8 \%)$. Similarly, the $\mathrm{W}$ content increased gradually in the inserts treated with one tempering cycle (CT1) compared to the inserts treated with four tempering cycles after the cryogenic treatment (CT4). However, it was less (W: 37.4\%) than the untreated inserts (W: 40.4).

The reduction in content of $\mathrm{W}$ after CT1 treatment could also be an indication of the formation of some other compounds, such as $\eta$-phase carbide. New peaks in XRD analysis (figure 3) after the treatments confirmed the transformation of $\mathrm{WC}$ to two new $\eta$-phase carbides: the binary phase $\mathrm{W}_{2} \mathrm{C}$ and ternary $\mathrm{Co}_{3} \mathrm{~W}_{3} \mathrm{C}$, which are harder and brittle in nature. It is well known that two types of the ternary phase compounds can be obtained in cobalt bonded tungsten carbide: $\mathrm{Co}_{3} \mathrm{~W}_{3} \mathrm{C}$ and $\mathrm{Co}_{6} \mathrm{~W}_{6} \mathrm{C}$. The latter exists only at the substrate/coating interface (Seah et al 2003; Vadivel and Rudramoorthy 2009), which in this case, does not exist, as the selected tungsten carbide insert was uncoated. The $\eta$-phase carbides are formed under the condition of carbon deficit, and non-uniformly distributed carbon in the hard metal during sintering, and occupy the volume formerly occupied by the cobalt (Lavergne et al 2002). The transformations are according to the distribution states of $\mathrm{W}, \mathrm{Co}$ and $\mathrm{C}$ phases in the material.

\subsection{X-ray diffraction $(X R D)$}

All the untreated and multi-tempered WC-Co inserts were analysed using X-ray diffractometer, to assess the possible phase changes. Typical XRD profiles pertaining to all the untreated and treated inserts are presented in figure 3. All samples showed peaks corresponding to tungsten carbide (WC), di-tungsten carbide $\left(\mathrm{W}_{2} \mathrm{C}\right)$ and its complex carbide $\eta$-phase compound $\left(\mathrm{Co}_{3} \mathrm{~W}_{3} \mathrm{C}\right)$, and no contaminants were observed in any of the samples. Even though there was no evidence of $\eta$-phase in the untreated WC-Co samples as per XRD results (figure 3a), the existence cannot be neglected if the amount of this phase was below the detection limits of XRD. General XRD patterns of the treated inserts were very similar to the untreated samples. However, there was indication of the presence of $\mathrm{W}_{2} \mathrm{C}$ compound (at various $2 \theta$ positions) in all treated and $\mathrm{Co}_{3} \mathrm{~W}_{3} \mathrm{C}$ complex carbide compound (at around $35^{\circ}$ ) in CT2, CT3 and CT4 treated inserts, in addition to those of the major compound (WC) with the highest peak either of WC $\left(\begin{array}{lll}0 & 1 & 0\end{array}\right)$ or WC $\left(\begin{array}{lll}0 & 1 & 1\end{array}\right)$ plane found around $35^{\circ}$ or $48^{\circ}$. A small independent peak corresponding to $\mathrm{Co}_{3} \mathrm{~W}_{3} \mathrm{C}$ complex carbide compound was also observed around $40^{\circ}$ in the samples treated with CT2, CT3 and CT4, indicating its presence. Besides the presence of all three carbides within the tableau, most of the samples contained a mixture of two/three carbides. All the specimens containing a mixture of carbides were having WC as one of these.

In this computerized analysis, the presence of the $\eta$-phase carbide along with primary carbides (WC), must be due to the reason that secondary carbides ( $\eta$-phase carbides) were of the same family and got converted from the primary carbides (WC) only. The $\eta$-phase carbides are hard brittle cubic lattice compounds that reduce the fracture toughness of cemented carbide and must be controlled. The newly formed fine $\eta$ phase carbide compounds in a fine and dense structure of cobalt after the treatment formed a tougher and coherent structure with the most stable form. These newly formed $\eta$ phase carbides also played a vital role in improving the properties of the material but with controlled number of the three tempering after the cryogenic treatment. Cryogenic treatment enhanced the stresses and hardness in the material that made the material brittle, unsuitable for high-impact energies 

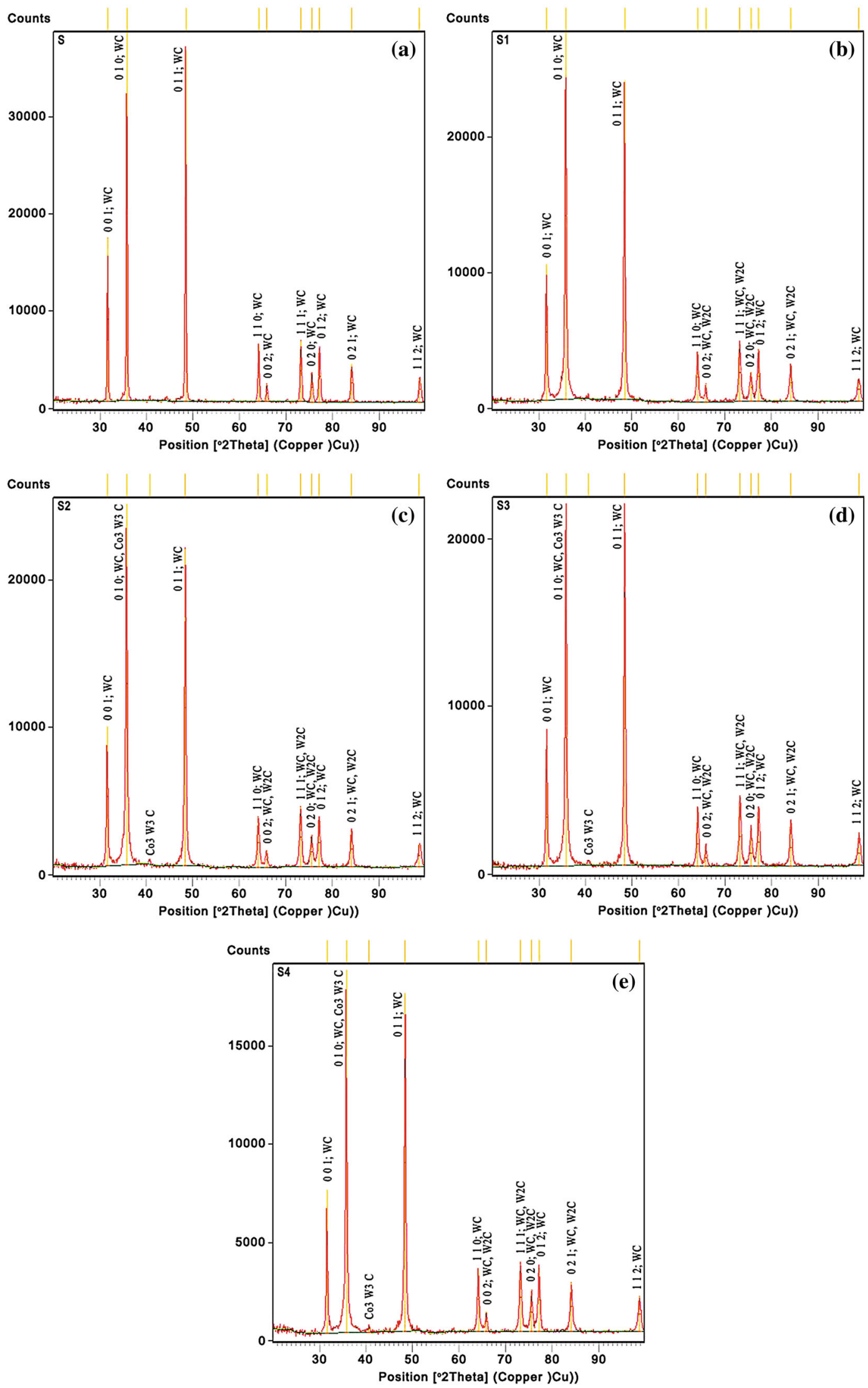

Figure 3. XRD profiles for tungsten carbide inserts: (a) un-treated, (b) CT1 treated, (c) CT2 treated, (d) CT3 treated and (e) CT4 treated. 
during its service. A limited number of tempering cycles after the cryogenic treatment helped in releasing the stresses and reducing the brittleness, to some extent, to make the material a better performer. The resulted stabilization of the material for its maximum performance may be attributed to attain the lowest energy level by WC-Co material during its cryogenic treatment and then taken back to room condition after the three tempering cycles at $200{ }^{\circ} \mathrm{C}$. So, it is always important to apply limited numbers of tempering cycles after the cryogenic treatment to make the material stress-free and more stable. An increased number of tempering cycles, as in CT4 treated inserts, made the binding material ( $\beta$-phase) softer and reduced the effectiveness of the cryogenic treatment as also deduced from figure 2 . The presence of newly formed $\eta$-phase complex carbides were found to be low compared to the other treated ones, which led to the conclusion that due to cryogenic treatment and tempering, few of the primary carbides were converted to $\eta$-phase complex carbides, that improved the wear resistance, due to increase in the hardness and toughness.

\subsection{Micro-hardness}

The average values of micro-hardness on Viker's scale along with standard deviation (SD) for all treated, and untreated WC-Co inserts are shown in figure 4. Micro-hardness of all treated inserts was more compared to that of the untreated inserts. However, there was a gradual decrease in hardness with the numbers of tempering cycles after the cryogenic treatment (CT4). CT1 treated inserts had significantly higher hardness, approximately $15.2 \%$ higher than that of the untreated inserts. However, it gradually reduced to approximately $2.8 \%$ in case of the CT4 treated inserts. These findings agree with previous studies (Thakur et al 2008; Gill et al 2012), which were not clear about the changes with multi-tempering after the cryogenic treatment.

Micro-hardness results can be primarily related to two possibilities: the first effect was the densification of the cobalt binder after the cryogenic treatment. By densification, the porosity was decreased, and the hardness increased. However, increasing number of tempering cycles after cryogenic

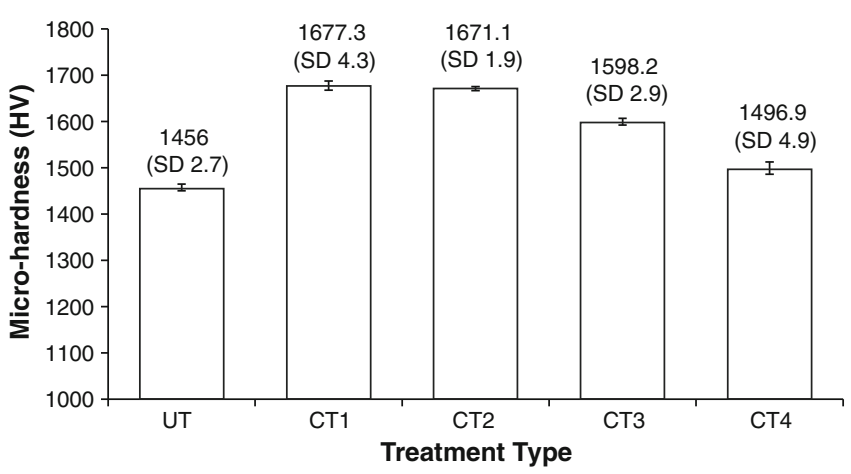

Figure 4. Micro-hardness of the samples. treatment weakened the effect of cryogenic treatment on the cobalt binder, resulted in decrease in hardness. The second effect was the development of stresses, which restricted the indenter penetration. The inserts contained tungsten carbide and cobalt, which have a large difference between the coefficients of thermal expansion. The values are $5.5 \times 10^{-6}$ and $14.2 \times 10^{-6} \mathrm{~K}^{-1}$ for tungsten carbide and cobalt respectively (Chawla et al 2003). During cryogenic treatment, the carbide phase was subjected to compressive stresses and the cobalt phase to tensile ones. These uneven structural changes which occurred due to normal contractions were opposed by transformation expansion at this temperature. This phenomenon developed residual stresses in the material, which led to an increase in the strength of the carbide with decrease in ductility of the cobalt phase, resulting in higher value of the hardness in this brittle phase. These stresses also play an important role to affect the mechanical properties of these materials. Reheating hardened WC-Co during the tempering, tried to stabilize the material by releasing the stresses present in cryogenically treated inserts, which also exhibited a decrease in hardness and led to reduction of the brittleness. However, repeated tempering cycles decreased the hardness due to thermal softening effect, as indicated by the coarse and scattered structure (figure 2e). Tungsten carbide being a more stable structure, these changes probably occurred in the cobalt binder and the magnitude of these stresses in the cementing phase depends upon the content of the cobalt (Stewart 2004; Thakur et al 2008). The change in micro-hardness value was low due to controlled rate of change of temperature in this study. The values could have been higher, if the rate of change of temperature during the cryogenic treatment would have been very fast, as also reported by Thakur et al (2008) in their different studies on the tungsten carbide-cobalt cutting inserts. However, there was a possibility of crack formation, due to sudden change in the temperature, which was not desired for better performance of the inserts. Secondly, the formation of complex carbide compounds such as $\eta$-phase (figure 3 ) during the cryogenic treatment, which are harder in nature, could be another reason for an increase in hardness. Still, it can be noted that hardness value cannot be considered as an exact parameter in evaluation of wear-resistance of the cryogenically treated inserts.

\subsection{Wear analysis}

The cryogenically treated inserts showed significant improvement in wear-resistance. Flank wear of CT1, CT2, CT3 and CT4 treated inserts (figure 5) at cutting speed of $42.20 \mathrm{~m} / \mathrm{min}$, was found $23.6 \%, 24.7 \%, 25.4 \%$ and $25.4 \%$ lesser respectively than that of the untreated inserts, when machining was performed at feed rate of $0.04 \mathrm{~mm} / \mathrm{rev}$. It was $19.3 \%, 20.7 \%, 21.4 \%$ and $21.0 \%$ lesser at the feed rate of $0.057 \mathrm{~mm} / \mathrm{rev}$ and $17.0 \%, 18.4 \%, 19.5 \%$ and $17.8 \%$ lesser respectively, when machining was performed at feed rate of 
(a)

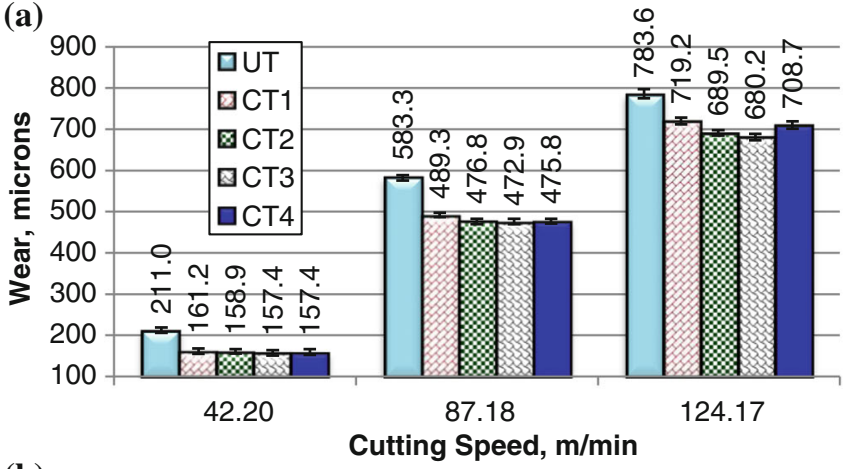

(b)

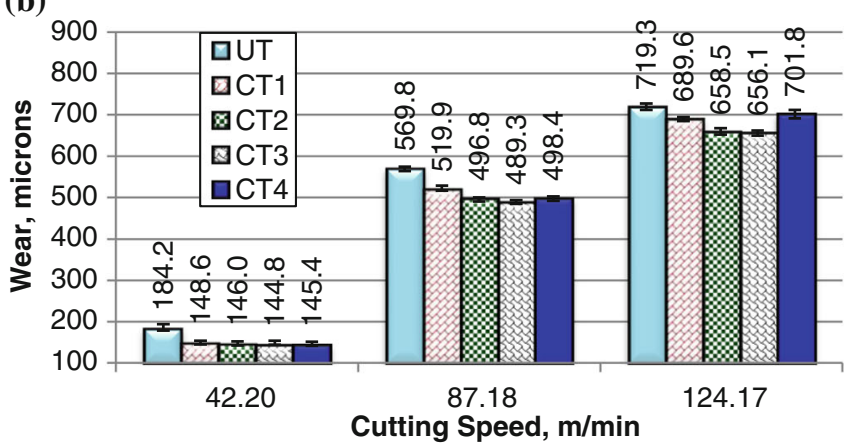

(c)

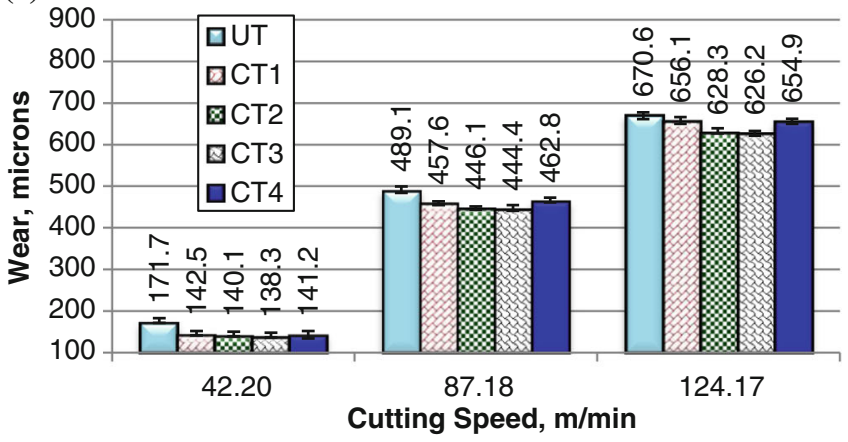

Figure 5. Wear vs cutting speed at (a) $0.04 \mathrm{~mm} / \mathrm{rev}$, (b) $0.057 \mathrm{~mm} / \mathrm{rev}$ and (c) $0.08 \mathrm{~mm} / \mathrm{rev}$ feed rate.

$0.08 \mathrm{~mm} / \mathrm{rev}$. Similarly, flank wear of CT1, CT2, CT3 and CT4 treated inserts, at cutting speed of $87.18 \mathrm{~m} / \mathrm{min}$, was found to be $16.1 \%, 18.3 \%, 18.9 \%$ and $18.4 \%$ lesser respectively than that of the untreated inserts, when machining was performed at the feed rate of $0.04 \mathrm{~mm} / \mathrm{rev}$. It was $8.8 \%$, $12.8 \%, 14.1 \%$ and $12.5 \%$ lesser respectively at feed rate of $0.057 \mathrm{~mm} / \mathrm{rev}$ and $6.4 \%, 8.8 \%, 9.1 \%$ and $5.4 \%$ lesser respectively, when machining was performed at the feed rate of $0.08 \mathrm{~mm} / \mathrm{rev}$. Flank wear of CT1, CT2, CT3 and CT4 treated inserts, at cutting speed of $124.17 \mathrm{~m} / \mathrm{min}$, was found $8.2 \%$, $12.0 \%, 13.2 \%$ and $9.6 \%$ lesser respectively than that of the untreated inserts, when machining was performed at feed rate of $0.04 \mathrm{~mm} / \mathrm{rev}$. It was $4.1 \%, 8.5 \%, 8.8 \%$ and $2.4 \%$ lesser respectively, at the feed rate of $0.057 \mathrm{~mm} / \mathrm{rev}$ and $2.2 \%$, $6.3 \%, 6.6 \%$ and $2.3 \%$ lesser respectively, when machining was performed at the feed rate of $0.08 \mathrm{~mm} / \mathrm{rev}$.

There was a gradual decrease in the wear observed in single tempered (CT1) to triple tempered (CT3), samples for all cutting conditions as depicted in figure 5. However, the wear was slightly higher when the inserts were treated with four tempering cycles after the cryogenic treatment (CT4). Though the maximum reduction of tool wear was shown by CT3 treated inserts, the value was the highest $(25.42 \%)$ at lower cutting conditions, as illustrated in figure 5(a).

Higher wear rate of untreated inserts during the turning operation can primarily be attributed to a rough surface, which was due to coarse carbide structure as illustrated in the micrograph (figure 2a). Gradual decrease in the wear for single tempered (CT1) to triple tempered (CT3) inserts can be attributed to better wear-resistance of the inserts. However, higher wear in case of the inserts treated with four tempering cycles after cryogenic treatment (CT4) was due to reduced effect of the cryogenic treatment. Even though hardness of CT1 and CT2 treated inserts was higher than that of CT3 treated inserts, the latter performed better. Apparently, there is no direct relation between the hardness and wear-resistance.

Improvement in the performance from single tempered to triple tempered cryogenically treated inserts can be explained as follows. Firstly, it is due to reduction in brittle behaviour of cobalt binder; secondly, by creation of a fine, compact and tougher matrix of cobalt phase, and the uniform distribution of carbides, which can be said to impart wear-resistance in the inserts during the machining process (Stewart 2004; Thakur et al 2008); and, thirdly, by formation of the complex carbides in $\eta$-phase, which are harder, and being in a tougher matrix of cobalt, help in improving wear-resistance in the inserts (Seah et al 2003; Thakur et al 2008; Vadivel and Rudramoorthy 2009). The deterioration of CT4 treated inserts took place due to two reasons. Firstly, the cobalt phase coarsened and the distribution of the carbides was not uniform, as evident from figure 2(e). Secondly, it was because of lesser value of the hardness (figure 4), which was due to ductile behaviour of cobalt phase after repeated tempering during CT4. The maximum reduction of tool wear was shown by CT3 treated inserts, which was $25.42 \%$ at lower cutting conditions, as illustrated in the figure 5(a). Better performance of the cutting tool inserts could be due to modest cutting zone temperature during machining, which did not influence the cryogenic properties of the inserts. Loss of cryogenic properties occurred at higher cutting conditions, which can be related to rise in cutting zone temperature, resulting in poor performance of the inserts.

Further, it can also be observed that number of tempering cycles after the cryogenic treatment did not influence the performance of the inserts much, while machining at lower cutting conditions. The wear of the inserts was almost similar. There could be two possible reasons. Firstly, the cutting zone temperature while machining at the low cutting conditions was less, which did not influence the cryogenic properties of the inserts. Secondly, forces acting on the inserts during lower cutting conditions were minimum (as this is the general machining trend). So, little brittleness, which was due to harder cobalt binder during CT1 and CT2 treatment, did not much influence the tool wear behaviour. 


\section{Conclusions}

The following key conclusions have been drawn from this study:

(I) Controlled cryogenic treatment helped in fineness, uniform distribution and densification of cobalt binder that held the carbides more firmly for better wear-resistance.

(II) Formation of $\mathrm{W}_{2} \mathrm{C}$ and $\mathrm{Co}_{3} \mathrm{~W}_{3} \mathrm{C}$ secondary carbides, along with fine and dense cobalt binder, created a stressfree harder and tougher matrix after cryogenic treatment and thereby improved performance of the inserts.

(III) Cryogenic treatment improved the micro-hardness of inserts. However, micro-hardness decreased with an increase in the number of tempering cycles after the treatment.

(IV) Wear-resistance of CT2 and CT3 treated inserts was the highest when the machining (turning) was performed at low cutting conditions and deteriorated with the rise in cutting conditions.

(V) At the low cutting conditions, number of tempering cycles influenced the performance marginally, whereas it played an important role at higher cutting conditions.

(VI) CT3 treated inserts showed the most significant improvement with marginal difference than CT2 treated inserts.

\section{Acknowledgement}

The authors gratefully acknowledge the financial grant provided by All India Council for Technical Education, New Delhi, India under Research Promotion Scheme, file no. 8023/BOR/RID/RPS-143/2008-09 and 8023/BOR/RID/ RPS-73/2009-10 to carry out this research.

\section{References}

ASTM B390-92 2000 Standard practice for evaluating apparent grain size and distribution of cemented tungsten carbide. Annual book of ASTM standards, Vol. 02(05)

ASTM B657-92 2000 Standard method for metallograpic determination of microstructure in cemented carbides. Annual book of ASTM standards, Vol. 02(05)

Bal K S 2012 Performance appraisal of cryo-treated tool by turning operation. Master's Thesis, Department of Mechanical Engineering, National Institute of Technology, Rourkela

Bensely A, Prabhakaran A, Lal D M and Nagarajan G 2005 Cryogenics 45747

Bryson W E 1999 Cryogenics (Ohio: USA Hanser Gardner Publications) 81

Buss K 2004 High temperature deformation mechanisms of cemented carbides and cermets. Thesis EPFL No. 3095, Chalmers University of Technology, Gothemburg, Sweden

Cajner F, Leskovsek V, Landek D and Cajner H 2009 Mater. Manuf. Process. 24743
Chawla N, Patel B V, Koopman M, Chawla K K, Saha R, Patterson B R, Fuller E R and Langer S A 2003 Mater. Charact. 49395

Choi N S, Kim Y B, Kim T W and Rhee K Y 2003 J. Mater. Sci. 38 1013

Gallagher A H, Agosti C D and Roth J T 2005 Trans. North Am. Manuf. Res. Inst. S.M.E. 33153

Gill S S, Singh R, Singh H and Singh J 2008 Int. J. Mach. Tools Manuf. 49256

Gill S S, Singh H, Singh R and Singh J 2010 Int. J. Adv. Manuf. Technol. 48175

Gill S S, Singh J, Singh H and Singh R 2012 Int. J. Manuf. Technol. $\mathbf{5 8} 119$

Gisip J, Gazo R and Stewart H A 2009 J. Mater. Process. Technol. 2095117

ISO 36851993 Tool-life testing with single-point turning tools, ICS 25:100:10

Kalsi N S, Sehgal R and Sharma V S 2010 Mater. Manuf. Process 251077

Kalsi N S, Sehgal R and Sharma V S 2012 Adv. Mater. Research. 410267

Krar S, Gill A and Smid P 2008 Technology of Machine Tools, 6th edition (New Delhi: McGraw-Hill Education (I) Pvt Ltd.) 223

Lavergne O, Robaut F, Hodaj F and Allibert C H 2002 Acta Materialia 501683

Oberg E, Jones F D, Horton H L, Ryffel H H, McCauley C J, Heald R M and Hussain M I 2004 Machinery's Handbook (New York: Industrial Press) 271009

Podgornik B, Leskovsek V and Vizintin J 2009 Mater. Manuf. Process. 24734

Reddy T V S, Kumar B S A, Reddy M V and Venkataram R 2007 Improvement of tool life of cryogenically treated P-30 tools. Proceedings of International Conference on Advanced Materials and Composites (ICAMC-2007) at the National Institute for Interdisciplinary Science and Technology, CSIR, Trivandrum, India, p. 457

Reddy T V S, Kumar T S, Reddy M V and Venkatram R 2008 Cryogenics $\mathbf{4 8} 458$

Reddy T V S, Kumar T S, Reddy M V and Venkatram R 2009 Int. J. Refrct. Met. Hard Mater. 27181

Richetti A, Machado A R, DaSilva M, Ezugwu B E O and Bonney J 2004 Int. J. Mach. Tools. Manuf. 44695

Sarin V K 1981 Advances in Powder Technology ASM (ed.) D Y Chin 253

Seah K H W, Rahman M and Yong K H 2003 Proc. Inst. Mech. Eng. Part B-J Eng. Manuf 21729

Steward H 2008 FDM, ABI/INFORM Global. 8064

Stewart H A 2004 For. Prod. J. 5453

Thakur D, Ramamoorthy B and Vijayaraghavan L 2008 Mater. Lett. 624403

Vadivel K and Rudramoorthy R 2009 Int. J. Adv. Manuf. Technol. 42222

Yang H S, Jun Wang, Shen B L, Liu H H, Gao S J and Huang S J 2006 Wear 2611150

Yong A Y L, Seah K H W and Rahman M 2006 Int. J. Mach. Tools Manuf. 462051

Yong A Y L, Seah K H W and Rahman M 2007 Int. J. Adv. Manuf. Technol. 32638 